\title{
Hydroxypropyl- $\beta$-Cyclodextrin- Complexed Resveratrol Enhanced Antitumor Activity in a Cervical Cancer Model: In Vivo Analysis
}

\author{
Xincai Hao ${ }^{1 \dagger}$, Xiaodong Sun ${ }^{1 \dagger}$, Haizhen Zhu ${ }^{1}$, Lixia Xie ${ }^{1}$, Xuanbin Wang ${ }^{1}$, Nan Jiang ${ }^{2}$, \\ Pan $\mathrm{Fu}^{1 *}$ and Ming Sang ${ }^{1 *}$
}

${ }^{1}$ Hubei Clinical Institute of Parkinson's Disease at Xiangyang No .1 People's Hospital, Hubei Key Laboratory of Wudang Local Chinese Medicine Research, Hubei University of Medicine, Shiyan, China, ${ }^{2}$ Hubei Province Hospital of Traditional Chinese Medicine, Hubei Province Academy of Traditional Chinese Medicine, Wuhan, China

OPEN ACCESS

Edited by:

Jinming Zhang,

Chengdu University of Traditional

Chinese Medicine, China

Reviewed by:

Suresh Valiyaveettil,

National University of Singapore,

Singapore

Tongkai Chen,

Guangzhou University of Chinese

Medicine, China

*Correspondence:

$\mathrm{Pan} \mathrm{Fu}$

759310361@qq.com

Ming Sang

smxd2000@126.com

${ }^{\dagger}$ These authors have contributed equally to this work.

Specialty section: This article was submitted to Pharmacology of Anti-Cancer Drugs, a section of the journal

Frontiers in Pharmacology

Received: 02 July 2020 Accepted: 11 March 2021

Published: 15 April 2021

Citation:

Hao X, Sun X, Zhu H, Xie L, Wang $X$, Jiang N, Fu P and Sang M (2021)

Hydroxypropyl- $\beta$-Cyclodextrin-

Complexed Resveratrol Enhanced Antitumor Activity in a Cervical Cancer

Model: In Vivo Analysis.

Front. Pharmacol. 12:573909.

doi: 10.3389/fphar.2021.573909
Trans-resveratrol (RES) exhibits a wide range of biological activities. Various methodological approaches have been established to improve the pharmacokinetic properties of RES. Moreover, additional in vivo studies are required to support clinical application. In this study, RES/HP- $\beta-C D$ (RHSD) inclusion complex was prepared and characterized by FTIR, PXRD, DSC and NMR data. The effect and potential mechanism of $\mathrm{RHSD}$ against cervical cancer were investigated in a mouse xenograft tumor model by qPCR assay, Western blot assay, and immunohistochemical assay. Results showed that $\mathrm{RHSD}$ significantly decreased tumor growth compared with free RES, while the effect of preventing tumor growth was more prominent in vivo. Notably, RHSD could inhibit tumor development by suppressing the expression of HPV E6 and E7 oncogenes and upregulating P53 and Rb1 protein in cervical cancer. These findings demonstrated that RHSD was safe and potential for development of a new oral administration drug to treat cervical cancer.

Keywords: hydroxypropyl- $\beta$-cyclodextrin, resveratrol, cervical cancer, HPV E6 and E7, in vivo

\section{INTRODUCTION}

Cervical cancer is the second most common cancer of global cancer deaths among women (Ferlay et al., 2015). Over 500,000 new cases of cervical cancer are reported every year, and most cases are from developing countries (Chatterjee et al., 2019). HPV 16 and 18 are estimated to be associated with cervical cancer and precancerous lesions worldwide (Nubia et al., 2004; He et al., 2014). HPV E6 and E7 are two major oncoproteins encoded by HPV 16 and 18 (Tan et al., 2012), which play a central role in the onset of aging in HPV-positive cancer cells. High-risk HPV E6 and E7 proteins have been shown to promote tumorigenesis by promoting cell immortality and migration, changing cell cycle and apoptosis control, and avoiding host immune surveillance (Thomas and Chiang, 2005; Liu et al., 2009; De Sanjose et al., 2010; Ghittoni et al., 2010; Au Yeung et al., 2011). This cellular response is related to the regeneration of P53 and Rb1 anti-proliferative proteins (Scheffner et al., 1990; Dyson et al., 1992; Heck et al., 1992; Huibregtse et al., 1993; Taghizadeh et al., 2019). Therefore, inhibition of the E6/P53 and E7/Rb pathways is an effective therapeutic strategy for cervical cancer (Münger and Howley, 2002; He et al., 2014). Unfortunately, the current cancer prevention and treatment methods in developing countries have failed to significantly reduce cervical cancer 
mortality, because of the high costs originating from side effects of treatment. Therefore, non-toxic and low-cost natural products with anti-cancer properties have continued to attract great interest.

Trans-Resveratrol (3,5,4'-trihydroxy-trans-stilbene; RES), which belongs to the family of stilbestrol, is abundant in red wine, fruit, and vegetables. RES has shown a wide range of biological activities, including anti-inflammatory activity, antioxidant activity (Gambuti et al., 2004), cardiac protective action (Adrian et al., 2000), anti-aging (Hsu et al., 2014), and anticancer activity (Kulacki and Lamberti, 2008). Kim et al. have found that RES can suppress the migration and invasion of human cervical cancer cells (Kim et al., 2012). Liu et al. report that RES induce cervical cancer HeLa cell apoptosis through the activation and nuclear translocation promotion of FOXO3a (Liu et al., 2020). Li et al. have shown RES suppresses human cervical carcinoma cell proliferation and elevates apoptosis via the mitochondrial and p53 signaling pathways (Li et al., 2018). Chatterjee et al. and our team research also find that the anticervical cancer activities of RES are connected with expression of HPV E6 and E7 genes (Chatterjee et al., 2019; Sun et al., 2021). In addition, Clinical trials in humans have shown that RES is nontoxic to normal cells and are well-tolerated (Riche et al., 2013). However, the bioavailability of RES is not optimal due to its poor water solubility, which decreases its pharmacological effects because of its low absorption in oral administration.

Cyclodextrin (CD) inclusion complexes has been proved to be the most effective method to improve the solubility and dissolution of insoluble drugs (Tang et al., 2016). CD are equipped with a hydrophobic cavity to encapsulate another molecule forming a water-soluble complex through host-guest interactions. In particular, 2 -Hydroxypropyl- $\beta$-CD (HP- $\beta$-CD), modified cyclodextrin derived from $\beta-C D$, has high medicinal values in terms of increasing the guest's stability, oxidation and dehydration (Liu et al., 2006), improving dissolution rate, bioavailability (Loftsson and Brewster, 1996; Hsu et al., 2019), enhancing the permeation, prolonging the effect of medicine, reducing irritant and drug toxicity (Scavone et al., 2016; Tang et al., 2016). Previous research reported that the encapsulation of RES by HP- $\beta$-CD can increase its light stability, dissolution rate, and biological activity in vitro (Lucas-Abellán et al., 2008; Wei et al., 2017). However, in vivo studies are required to support its clinical application. To the best of our knowledge, no study on the RES/HP- $\beta$-CD (RHSD) inclusion complex against cervical cancer has been conducted. Therefore, the aim of this study was to investigate the anti-cervical cancer effects of RHSD in vivo and determine its related mechanism.

In this study, RHSD was prepared with the co-evaporation method under a 1:1 ration and characterized by Fourier transform infrared spectroscopy (FT-IR), powder X-ray diffraction (PXRD), and differential scanning calorimetry (DSC) and nuclear magnetic resonance (NMR). The solubility and dissolution rate were investigated in vitro, and the effect of the RSHD complex on cervical cancer was evaluated in a murine model of HeLa cell-induced cancer in vivo. Their preventive potential effect on cervical cancer was also evaluated.

\section{MATERIALS AND METHODS}

\section{Materials}

Analytical grade RES (purity 98.0\%) was purchased from Aladdin (Shanghai, China). HP- $\beta$-CD (average Mw $=1540 \mathrm{Da}$ with $1.0 \mathrm{M}$ substitution, hydroxypropyl moiety) were obtained from Aldrich (St. Louis, MO, United States). Ethanol (95\%, v/v) was purchased from Merck Co. (Santa Ana, CA, United States). Water was double distilled and deionized. Human cervical carcinoma (HeLa) cells were provided by the Central Laboratory at the affiliated Xiangyang No.1 People's Hospital of Hubei University of Medicine (Shiyan, China). HeLa cells were grown in $175 \mathrm{~cm}^{2}$ glass culture flasks dissolved in $30 \mathrm{ml}$ of DMEM supplemented with $10 \%(\mathrm{v} / \mathrm{v})$ fetal bovine serum (FBS) and $100 \mathrm{IU} / \mathrm{ml}$ penicillin $\mathrm{G}$ sodium and $100 \mathrm{mg} / \mathrm{ml}$ streptomycin sulfate. The cells were stored in an incubator at $37^{\circ} \mathrm{C}$ with $5 \% \mathrm{CO}_{2} / 95 \%$ air humidified atmosphere, subcultured three times per week, and used for the experiments when in exponential growth phase. Rabbit antihuman HPV18 E6, mouse anti-human P53, mouse antihuman $\mathrm{Rb} 1$, rabbit anti-human $\beta$-actin, and mouse antihuman GAPDH antibodies were purchased from Absin Biotechnology Co., Ltd (Shanghai, China). Rabbit anti-human HPV18 E7 antibody was purchased from Abcam (Cambridge, United Kingdom).

\section{Preparation of RES-HP- $\beta$-CD Complexes and Physical Mixtures}

An inclusion complex of 1:1 $\mathrm{M}$ ratio was prepared by coevaporation. Approximately $0.82 \mathrm{~g}$ of $\operatorname{RES}(\mathrm{Mw}=228 \mathrm{Da})$ and $5.54 \mathrm{~g}$ of $\mathrm{HP}-\beta-\mathrm{CD}(\mathrm{Mw}=1540 \mathrm{Da})$ were dissolved in $40 \mathrm{ml}$ of alcohol, respectively. RES solution and HP- $\beta-\mathrm{CD}$ solution were mixed in a sealed glass vial and agitated for $24 \mathrm{~h}$ at room temperature to obtain a clear solution. The sample was evaporated under reduced pressure in a rotary evaporator at $40^{\circ} \mathrm{C}$ to obtain a solid inclusion complex. A homogeneous physical mixture of RES and HP- $\beta$-CD (1:1 M ratio) was prepared by grinding the mixture with a mortar.

\section{Solubility Study}

The solubility of RES and RHSD was studied based on a previously reported method. In brief, excess RES (20 mg) or RHSD complexes $(140 \mathrm{mg})$ were mixed with water $(5 \mathrm{ml})$ respectively, and the mixture was stirred at $25^{\circ} \mathrm{C}$ for $72 \mathrm{~h}$. The samples were centrifuged at $15,000 \times g$ for $10 \mathrm{~min}$ to remove excess insoluble substance. The amount of RES was measured using HPLC.

\section{Particle Size Distribution}

The particle size and polydispersity indexes (PDI) of HP- $\beta-C D$ and RHSD were measured by Nano ZS90 laser light scattering instrument (Malvern, PA, United States). Briefly, $0.8 \mathrm{mg} / \mathrm{ml}$ of HP- $\beta-C D$ and RHSD aqueous solutions were prepared, respectively. After filtered through a 0.45 um hydrophilic membrane filter, the samples were examined. 


\section{Dissolution Study}

The dissolution experiments were performed in normal saline by rotating basket method. Briefly, in each dissolution test, RES $(25 \mathrm{mg})$ and RHSD $(175 \mathrm{mg})$ were weighed and added into dissolution medium in a cell of dissolution tester (Rcz-6c3, Shanghai Huanghai Pharmaceutical Inspection Instrument Co., Ltd: Shanghai, China) and stirred with a speed of $100 \mathrm{rpm}$ at $37^{\circ} \mathrm{C}$. Aliquots (5 ml each) were withdrawn at 5, 10, 15, 20, 30, 45, 60, 90 and $120 \mathrm{~min}$ and immediately filtrated through a membrane filter (0.45 um). At each sampling time, an equal volume of fresh medium was added to the tester cell and the correction for the cumulative dilution was calculated. The concentrations of RES in the filtrated solutions were measured by UV-spectrophotometer at $306 \mathrm{um}$.

\section{Characterization of Inclusion Complex Fourier Transform Infrared Spectroscopy}

RES, HP- $\beta-C D$, physical mixture, and RHSD complex were measured with an FT-IR spectrometer (Thermo Fisher Scientific, Nicolet iS10, United States). The scanning scope was in the range of $4000-400 \mathrm{~cm}^{-1}$. All samples were applied to the spectrometer directly.

\section{Powder X-Ray Diffraction}

The PXRD spectra of RES, HP- $\beta-C D$, physical mixture, and RHSD were recorded on an X-ray diffractometer (Bruker) with $\mathrm{Cu} \mathrm{Ka}$ radiation. The voltage and current were $45 \mathrm{kV}$ and $40 \mathrm{~mA}$, respectively. The scan rate was $16^{\circ} / \mathrm{min}$ between $3^{\circ}$ and $60^{\circ}$ in the $2 \theta$ angle range.

\section{Differential Scanning Calorimetry}

RES, HP- $\beta-C D$, physical mixture, and RHSD were accurately weighed separately. Their DSC curves were measured with a Q200 differential scanning calorimeter (TA, United States) at $10^{\circ} \mathrm{C} /$ min between 30 and $320^{\circ} \mathrm{C}$ in nitrogen atmosphere. An empty pan was used as the reference for the test.

\section{${ }^{1} \mathrm{H}$ Nuclear Magnetic Resonance}

The ${ }^{1} \mathrm{H}$ NMR spectra of Res, HP- $\beta-\mathrm{CD}$ and RHSD complex spectra were tested with a Bruker Avance 600 spectrometer (Germany) at $600 \mathrm{MHz}$ all samples were dissolved with DMSO- $d_{6}$.

\section{Anti-tumor Efficacy of RES/HP- $\beta$-CD In Vivo}

Female athymic BALB/C nude mice weighing 14-20 g (4-6 weeks) were purchased from Hunan SJA Laboratory Animal Co., Ltd (Changsha, China). Mice were housed at a controlled temperature of $20-22^{\circ} \mathrm{C}$, with $50-60 \%$ relative humidity, and fed with a standard laboratory chow and tap water ad libitum. Mouse xenograft experiments in this study were complied with the ARRIVE guidelines and were conducted in accordance with the U.K. Animals (Scientific Procedures) Act, 1986 and associated guidelines. This study was approved by the Ethical Committee for Animal Experimentation of Xiangyang No.1 People's Hospital (NO. 2017DW008). Athymic BALB/C were divided into the prevention group and treatment group (18 animals each group, Figure 1). Every group involved the mice being randomly divided into three subgroups: vehicle (normal saline containing $1 \%$ ethanol), RES ( $30 \mathrm{mg} / \mathrm{kg}$, p. o.), and RHSD (30 mg/ kg, p. o.). Each subgroup comprised six mice. The HeLa cell suspension containing $2 \times 10^{6}$ cells in sterile saline was subcutaneously injected in the right flank of athymic BALB/C. Administration cycles were initiated in the treatment group when the tumor size reached approximately $100 \mathrm{~mm}^{3}$ (in 7 days). After 3 weeks, the mice were sacrificed. In the prevention group, the administration cycles were 42 days, and tumors were implanted on the 15th day after administration. The mice were sacrificed 4 weeks later.

Animals' tumor volumes and body weight were measured every 3 days by using the formula as previously described (Ao et al., 2019): tumor volume $=($ length $) \times(\text { width })^{2} \times 0.5$. The tumor-bearing mice were examined every 3 days for tumor growth by using a caliper. At the end of the administration, all mice were sacrificed by cervical dislocation, and tumors were isolated and weighed. RNA and protein were extracted and fixed in paraformaldehyde. Each tumor nodule was confirmed by hematoxylin-eosin staining.

\section{Western Blot Analysis}

Cancer tissues were homogenized in lysis buffer composed of $10 \mathrm{mM}$ Tris- $\mathrm{HCl}$ (pH 7.5), $150 \mathrm{mM} \mathrm{NaCl}, 1 \mathrm{mM}$ EDTA, $1 \mathrm{mM}$ EDTA, $50 \mathrm{mM}$ NaF, $0.5 \mathrm{mM}$ phenylmethylsulfonylfluoride, $1 \mathrm{mM}$ sodium vanadate, $1 \%$ Triton X-100, $0.5 \%$ Nonidet P-40, and $1 \mu \mathrm{g} / \mathrm{ml}$ aprotinin. Samples were centrifuged at $12,000 \times \mathrm{g}$ for $15 \mathrm{~min}$ at $4^{\circ} \mathrm{C}$. An aliquot of the supernatant was used to determine protein concentration (Bio-Rad DC Protein Assay, Bio-Rad Laboratories, Hercules, CA, United States). Protein aliquots were mixed with $5 \times$ loading buffer, electrophoresed on SDS-polyacrylamide gels, and transferred electrophoretically onto polyvinylidene difluoride membranes. The membranes were incubated with HPV18 E6, HPV18 E7, P53, $\mathrm{Rb} 1, \beta$-actin, and GAPDH antibodies for overnight at $4^{\circ} \mathrm{C}$. The blots were washed with tris-buffered saline and Tween-20, incubated with corresponding horseradish peroxidaseconjugated secondary antibody (Santa Cruz Biotechnology, Santa Cruz, CA, United States) for $1 \mathrm{~h}$ at room temperature, and developed using the ECL substrate (Thermo Fisher Scientific, Waltham, MA, United States). The relative amount of protein on the blots was determined by densitometry by Lab Works software (UVP, Upland, CA, United States). GAPDH was used as a loading control. The relative expression of HPV18 E6, HPV18 E7, P53, and $\mathrm{Rb} 1$ was computed as follows: sample gray value/GAPDH gray value. Primary antibodies were used at 1:500-1000 dilution, and secondary antibodies were used at 1:10,000 dilution.

\section{Real-Time Polymerase Chain Reaction}

Total RNA was isolated from cancer tissues using TRIzol reagent (Invitrogen). Reverse transcription was performed with $2 \mu \mathrm{g}$ of total RNA and M-MLV reverse transcriptase (Promega, Madison, WI, United States). PCR amplification was performed using Taq polymerase (Bio-Rad, Hercules, CA, United States) under the following conditions: denaturation at $94^{\circ} \mathrm{C}$ for $5 \mathrm{~min}$, followed by 40 cycles of denaturation for $30 \mathrm{~s}$ at $94^{\circ} \mathrm{C}$ and annealing and extension for $60 \mathrm{~s}$ at $60^{\circ} \mathrm{C}$. Real-time PCR was performed using 


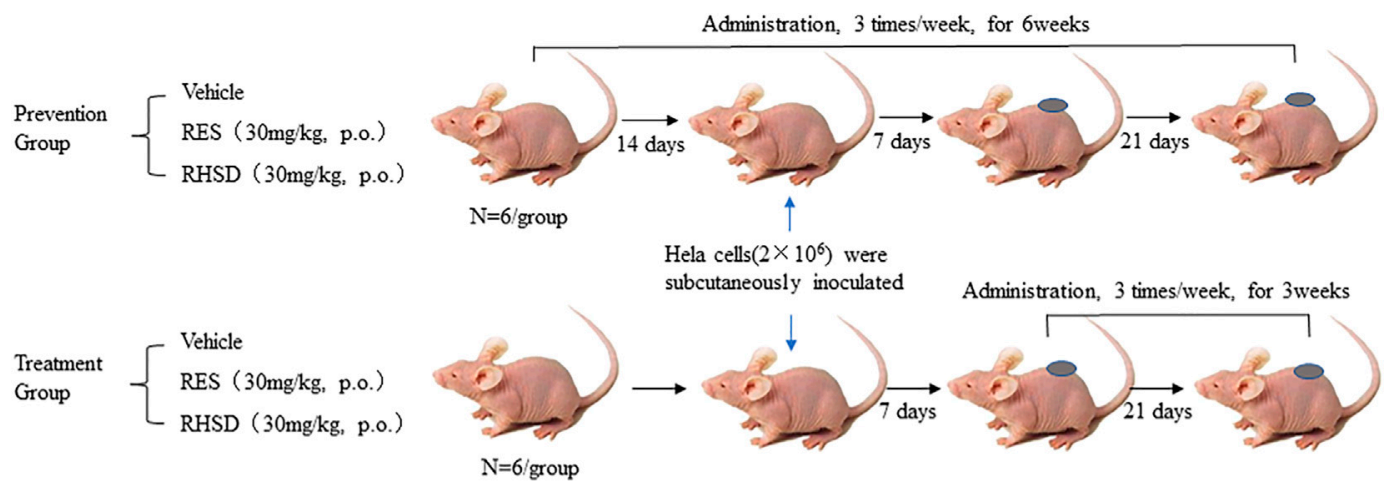

FIGURE 1 | Schematic representation of BALB/C female nude mice of cervical cancer model derived from tumor HeLa cells in vivo and subsequent treatment cycle.

the SYBR Green PCR Master Mix (Bio-Rad, Hercules, CA, United States) and a real-time PCR apparatus (IBA 7500, United States). The HPV18 E6 gene was amplified using the primers $5^{\prime}$-GCC AGAAACCGTTGAATCC-3' (forward) and 5'-AGTCTTTCC TGTCGTGCTCG-3' (reverse), whereas the HPV18 E7 gene was amplified using the primers $5^{\prime}$-GCATGGACCTAAGGC AACA-3' (forward) and $5^{\prime}$-CTCGTCGGGCTGGTAAAT- $3^{\prime}$ (reverse). GAPDH was used as an internal marker and amplified using the primers $5^{\prime}$-AGAAGGCTGGGGCTCATT TG-3' (forward) and $5^{\prime}$-AGGGGCCATC-CACAGTCTTC- $3^{\prime}$ (reverse). To calculate differential gene expression, we used the $2^{-\triangle \triangle \mathrm{Ct}}$ formula.

\section{H\&E Staining and IHC Assay}

Live and kidney organs obtained by $4 \%$ paraformaldehyde fixation were processed by paraffin section. The sections were stained with $\mathrm{H} \& \mathrm{E}$ and analyzed by histology and immunohistochemistry to evaluate organ metastasis, and examined under an inverted microscope (OLYPUS 75X Microscope, Tokyo, Japan). For the IHC assay of the expression levels of HPV18 E6, HPV18 E7, P53, and Rb1, the tumor paraffin-embedded sections were incubated with antihuman HPV18 E6, HPV18 E7, P53, and Rb1 primary antibodies. A biotinylated goat anti-rabbit antibody and rabbit anti-mouse antibody were used as secondary antibodies. The slides were washed with PBS and incubated with diaminobenzidine chromogen for 3-5 min to yield a dark brown color. The sections were counter-stained with hematoxylin for microscopic observation (OLYPUS 75X Microscope, Tokyo, Japan). The expression levels of HPV18 E6, HPV18 E7, P53, and Rb1 were calculated in five randomly selected areas in each tumor sample as the number of positive cells/total were counted at $\times 400$ magnification. Cells with moderate and strong brownish cytoplasmic staining were considered positive, whereas cells with unstained or weakly stained cytoplasm were considered negative.

\section{Statistical Analysis}

All the results are expressed as the mean \pm standard deviation (SD) for at least three independent experiments. Statistical differences were analyzed by independent sample t-tests. The differences between the experimental and control groups were compared by one-way ANOVA, followed by Dunnett's multiple comparisons test. Stata 7.0 (Stata Corp LP, College Station, TX, United States) was used. Values of $P<0.05$ were considered statistically significant.

\section{RESULTS}

\section{Solubilization and Dissolution Studies}

The solubility of RHSD was $4.18 \pm 0.44 \mathrm{mg}$ in pure water at $25^{\circ} \mathrm{C}$, which was 438.6 times higher than that of free RES $(0.00953 \pm$ $0.004 \mathrm{mg}$ ), indicating that HP- $\beta-C D$ was a more efficient solubilizer than raw RES. In Figure 2, the dissolution profile of the RHSD appeared to be much better than that of the RES. About $100 \%$ of the RES of complex amount dissolved within 10-20 min, while Less than $3 \%$ free RES was dissolved within $120 \mathrm{~min}$.

\section{Characterization of Inclusion Complex}

IR Figure 3A displays the IR spectra of free RES, HP- $\beta-C D$, physical mixture, and RHSD complex. Variations in IR peaks of guest or host are strong evidence for the occurrence of the

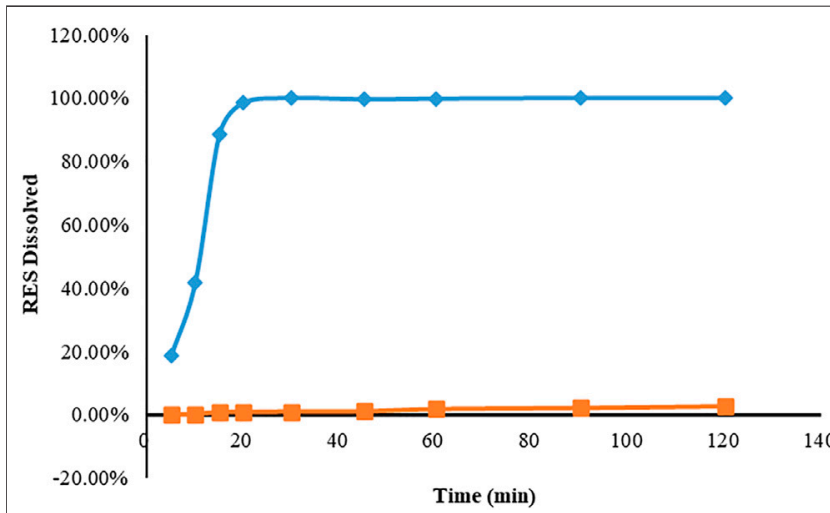

FIGURE 2 | Dissolution profiles of resveratrol (-) and inclusion complex $(\checkmark)$ in normal saline after $120 \mathrm{~min}$. The results were expressed according to the mean and standard deviation $(n=3)$ of the analyzes. 


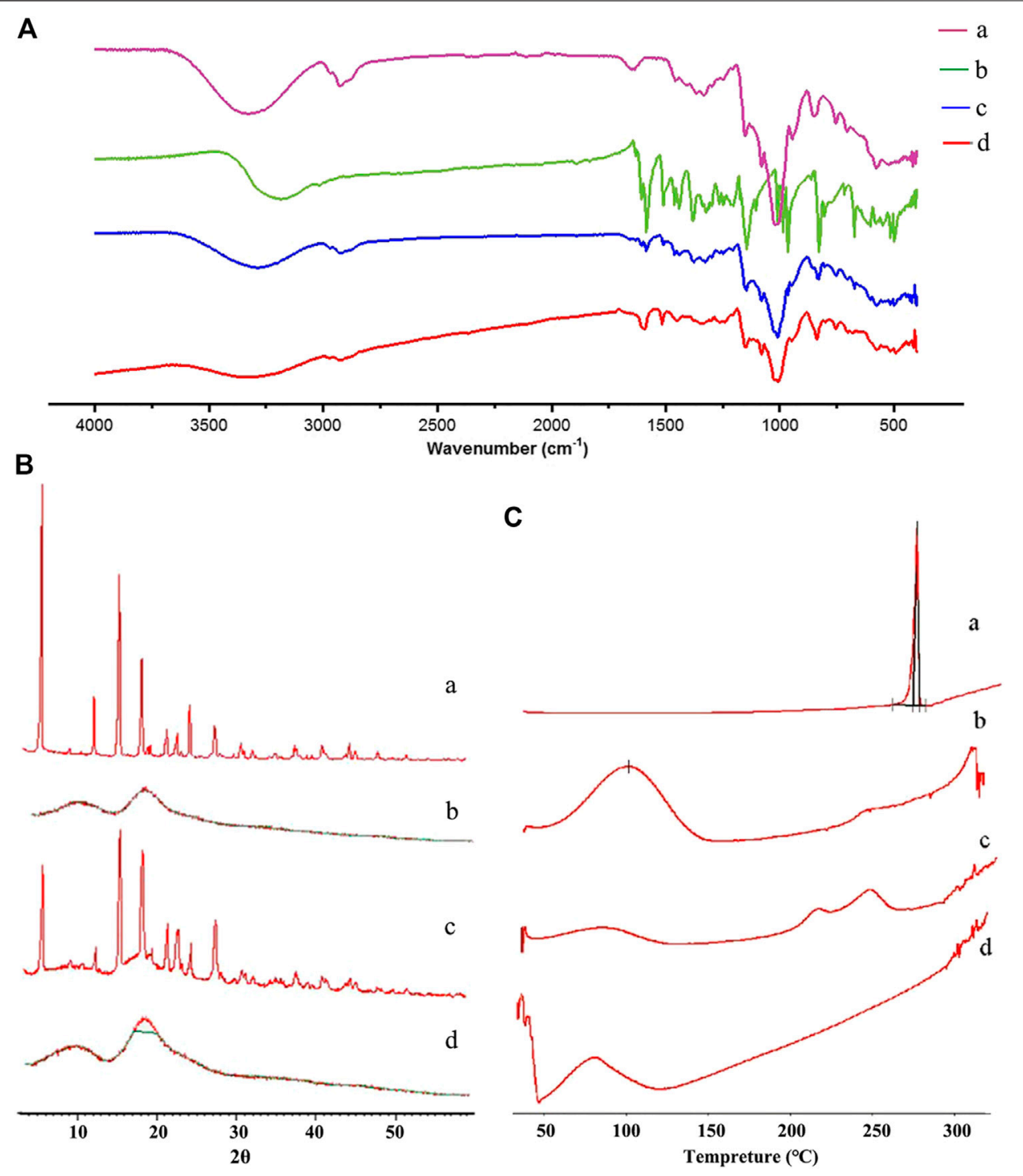

FIGURE 3 | FT-IR (A), PXRD (B), and DSC (C) spectra of RES (A), HP- $\beta-C D$ (B), physical mixture (C), and RHSD inclusion complex (D)

complex. The IR characteristic band of $\mathrm{O}-\mathrm{H}$ at $3185 \mathrm{~cm}^{-1}$ and the peaks at 1605,1583 , and $1510 \mathrm{~cm}^{-1}$ indicated the benzene ring of raw RES; these values were similar to previously reported findings (Zhang et al., 2013). The IR spectra of the physical mixture (Figure 3A-c) was the sum of the spectrum of HP- $\beta-C D$ and RES, showing no or a minor interaction in the physical mixture. The IR spectrum of the inclusion complex (Figure 3A-d) supported the formation of the complex. No absorption peaks were found at $1605 \mathrm{~cm}^{-1}$. The peak at $1583 \mathrm{~cm}^{-1}$ shifted to $1593 \mathrm{~cm}^{-1}$, and that at $1510 \mathrm{~cm}^{-1}$ shifted to $1515 \mathrm{~cm}^{-1}$. The disappearance and shift characteristics of the spectrum revealed the formation of the RHSD inclusion complex.

PXRD Figure 3B displays the PXRD spectra of free RES, HP$\beta-C D$, physical mixture, and RHSD complex. In the RES diffractogram, the diffraction peaks of Figures 3B-a indicated the crystalline form of RES. No crystalline peak was found in the HP- $\beta$-CD diffractogram (Figures 3B-b), indicating the amorphous form of HP- $\beta-\mathrm{CD}$. The physical mixture showed the sum diffraction peaks of two free components (Figures 3B-c). RHSD did not show a diffraction peak of RES (Figures 3B-d), indicating new amorphous formation.

DSC Figure 3C displays the DSC curves of free RES, HP$\beta-C D$, physical mixture, and RHSD. In the RES curve, the sharp endothermic peak at $264^{\circ} \mathrm{C}$, which was the melting point of RES, showed its crystalline form (Figures 3C). The thermogram of the $\mathrm{HP}-\beta-\mathrm{CD}$ curve presented a wide peak at $108^{\circ} \mathrm{C}$ (Figures $3 \mathbf{C}-\mathbf{b}$ ), which suggested a release of water molecules. The physical mixture displayed the sum thermogram peaks of two free components, which indicated that free RES and HP- $\beta-C D$ did not interact with each other (Figures $3 \mathrm{C}-\mathrm{c}$ ). In the RHSD 


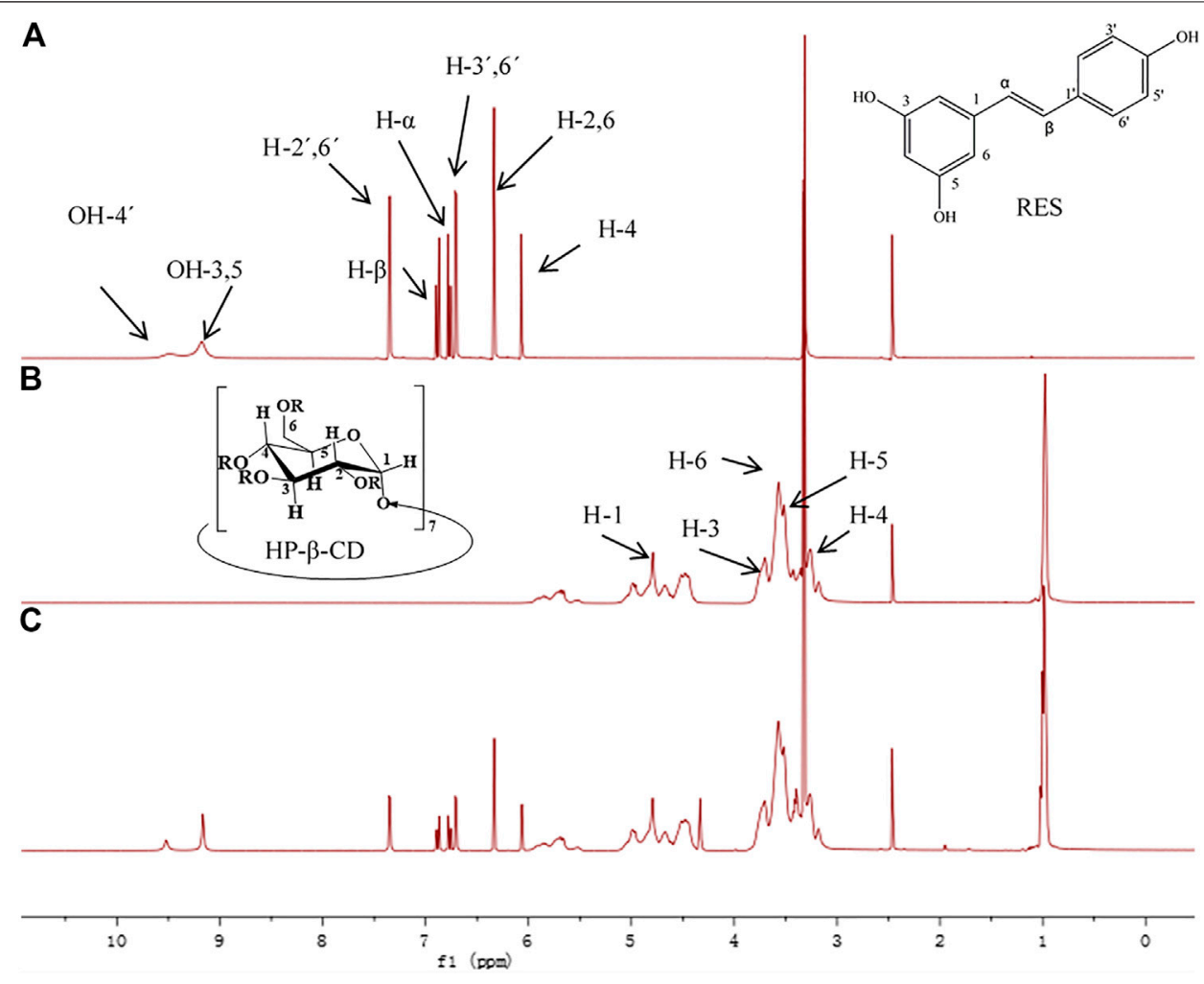

FIGURE 4 | The ${ }^{1} \mathrm{H}$ NMR spectra of resveratrol (A), HP- $\beta-C D$ (B) and the RHSD inclusion complex (C).

complex, the amorphous state was confirmed by the disappearance of the characteristic RES peak (Figures 3C-d). All the above findings supported the formation of stable complexes between RES and HP- $\beta$-CD.

${ }^{1} \mathrm{H}$ NMR Figure 4 displays sectra of free Res, HP- $\beta-\mathrm{CD}$ and RHSD complex. All chemical shifts and variation of the complexes are listed in Table 1. The chemical shifts of $\mathrm{H}-2$, H-6 and H-4 of Res have little variation by $\Delta \delta-0.005$ and $-0.004 \mathrm{ppm}$ respectively after complexation with HP- $\beta-C D$. These upfield shifts show that the benzene ring of Res enter the $\mathrm{CD}$ cavities. With the guest molecule into CD cavity, inside protons $(\mathrm{H}-3, \mathrm{H}-5)$ have upfield shift by $\Delta \delta-0.003 \mathrm{ppm}$ and $-0.002 \mathrm{ppm}$ for electron cloud shielding effection, while outside protons ( $\mathrm{H}-1, \mathrm{H}-2$ and $\mathrm{H}-4)$ have no shift upon complexation. The dates from ${ }^{1} \mathrm{H}$ NMR indicate that Res is embedded in to the HP- $\beta-C D$ cavity.

\section{Particle Size Distribution Analysis}

Cyclodextrins and their complexes can form large water-soluble aggregates to solubilize lipophilic water-insoluble drugs in aqueous solutions. The values of diameter and PDI of cyclodextrins are different after forming complexes. The value of PDI close to zero $(<0.10)$ indicates little variability in size (monodisperse), whereas values greater than 0.10 indicate polydisperse systems ( $\mathrm{Li}$ et al., 2015). As shown in Table 2. The differences values of PDI, and the higher diameters of complexes than HP- $\beta$-CD suggested RES was embedded into
HP- $\beta$-CD. Variability in PDI could be due to the tendency of the inclusion complex particles to agglomerate, because of the lack of significant net charge (no repulsive forces) to prevent particle agglomeration. Which maybe result the larger particle diameter of RHSD than HP- $\beta-C D$.

\section{RES/HP- $\beta$-CD and RES Inhibited Cervical Tumor Growth in the Mice Model}

Compared with free RES, the treatment and prevention efficacy of RHSD on HeLa xenografts in mice were evaluated. The tumor volume, tumor weight, and mice weight were measured and plotted after each treatment. As shown in Figure 5C, tumor growth in the prevention group was considerably slower than that in the treatment and vehicle groups. At the last day, the tumor volumes of the pre-RHSD and pre-RES groups were $130.23 \pm 38.12(p<0.01)$ and $353.31 \pm 43.52 \mathrm{~mm}^{3}(p<0.01)$, respectively. Meanwhile, the tumor volumes of the RHSD and RES treatment groups were $591.61 \pm 112.78(p<0.05)$ and $719.52 \pm 90.58 \mathrm{~mm}^{3}(p<0.05)$, respectively, whereas those of the pre-vehicle and vehicle groups were $992.3 \pm 73.16$ and $1102 \pm 129.37 \mathrm{~mm}^{3}$, respectively. The changes in tumor weight (Figure 5D) were the same as those in tumor volume. The tumor weights of the pre-RHSD and pre-RES groups were $0.137 \pm 0.077(p<0.01)$ and $0.203 \pm 0.054 \mathrm{~g}(p<0.01)$, respectively. Meanwhile, the tumor weights of the RHSD and RES treatment groups were $0.357 \pm 0.070(p<0.01)$ and $0.459 \pm$ 
TABLE 1 | Variation of the ${ }^{1} \mathrm{H}$ NMR chemical shifts (ppm) of Res and HP- $\beta-C D$ protons in free and complex states determined in DMSO-d6.

\begin{tabular}{|c|c|c|c|c|}
\hline Substance & Proton & Free $(\delta)$ & Complex ( $\delta$ ) & $\Delta \boldsymbol{\delta}$ \\
\hline \multirow[t]{6}{*}{ Res } & $\mathrm{H}-2,6$ & 6.338 & 6.333 & -0.005 \\
\hline & $\mathrm{H}-4$ & 6.069 & 6.065 & -0.004 \\
\hline & $a$ & 6.785 & 6.784 & -0.001 \\
\hline & $\beta$ & 6.898 & 6.897 & -0.001 \\
\hline & $\mathrm{H}-2^{\prime}, 6^{\prime}$ & 7.358 & 7.358 & 0 \\
\hline & $\mathrm{H}-3^{\prime}, 5^{\prime}$ & 6.716 & 6.715 & +0.001 \\
\hline \multirow[t]{6}{*}{$H P-\beta-C D$} & $\mathrm{H}-1$ & 4.791 & 4.791 & 0 \\
\hline & $\mathrm{H}-2$ & 3.396 & 3.396 & 0 \\
\hline & $\mathrm{H}-3$ & 3.705 & 3.702 & -0.003 \\
\hline & $\mathrm{H}-4$ & 3.259 & 3.259 & 0 \\
\hline & $\mathrm{H}-5$ & 3.517 & 3.515 & -0.002 \\
\hline & $\mathrm{H}-6$ & 3.570 & 3.570 & 0 \\
\hline
\end{tabular}

TABLE 2 | Polydispersity indexes (PDI) and average diameter of HP- $\beta-C D$ and the RHSD complex.

\begin{tabular}{lcc} 
Sample & Polydispersity index & Particle diameter $(\mathbf{n m})$ \\
\hline HP- $\beta$-CD & $0.615 \pm 0.334$ & $119.1 \pm 22.370$ \\
RHSD & $0.609 \pm 0.176$ & $227.2 \pm 6.568$
\end{tabular}

$0.096 \mathrm{~g}(p<0.01)$, respectively. The tumor weights of the prevehicle and vehicle groups were $0.541 \pm 0.073$ and $0.674 \pm 0.186$ $\mathrm{g}$, respectively. The tumor weight of the pre-RHSD group was lighter than that of the RHSD group $(p<0.01)$. The same trend was observed in the pre-RES and RES groups. In addition, the tumor weight of RHSD was lighter than that of RES in the prevention and treatment groups $(p<0.05)$. The mice maintained a slow rate of weight gain for the two groups in the early stage of the experiment (36 days; Figure 5B), and the pre-RES, RES, and vehicle groups demonstrated a sharp drop. However, the weights of the pre-RHSD and RES groups maintained an upward trend. At the last day, the mice weights of the pre-RHSD and RHSD groups were $21.75 \pm$ 1.16 and $21.27 \pm 0.93 \mathrm{~g}$, respectively, whereas those of the pre-RES and RES groups were $16.9 \pm 1.01$ and $16.95 \pm$ $1.35 \mathrm{~g}$, respectively. The mice weight of the vehicle group was $16.47 \pm 1.66 \mathrm{~g}$. The average mice weight between each group did not significantly differ. On the basis of the results, the effects of RHSD on the tumor volume and weight were stronger than the effects of RES in the prevention and treatment groups compared with the vehicle group. Therefore, the RHSD complex enhanced prevention and antitumor activity compared with free RES.

\section{RES/HP- $\beta-C D$ and RES Inhibited the Expression of HPV18 E6/E7 and Increased the Expression of P53 and Rb1 in vivo}

E6 and E7 proteins have been reported to play a critical role in the proliferation of cervical cancer cells. The suppression of viral E6 and E7 oncogene expression has been linked to apoptosis in cervical cancer cells. These findings led us to investigate whether the E6 and E7 oncogenes are attenuated by RHSD and RES. As

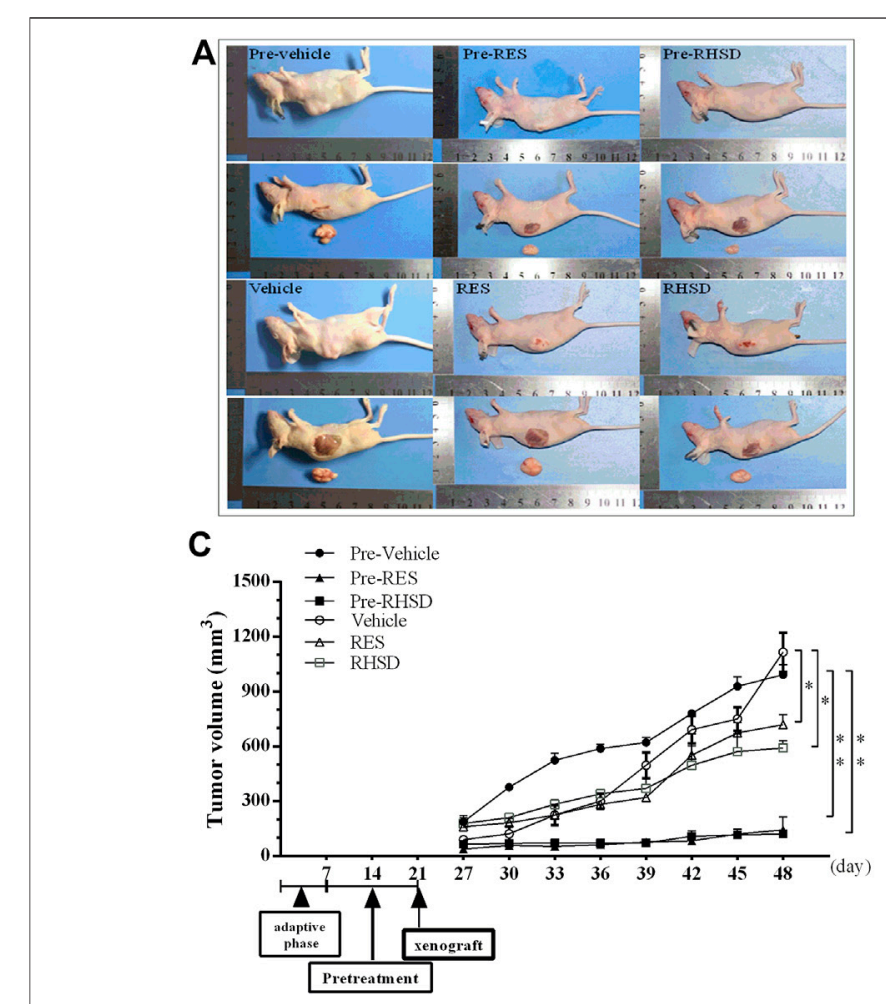

B
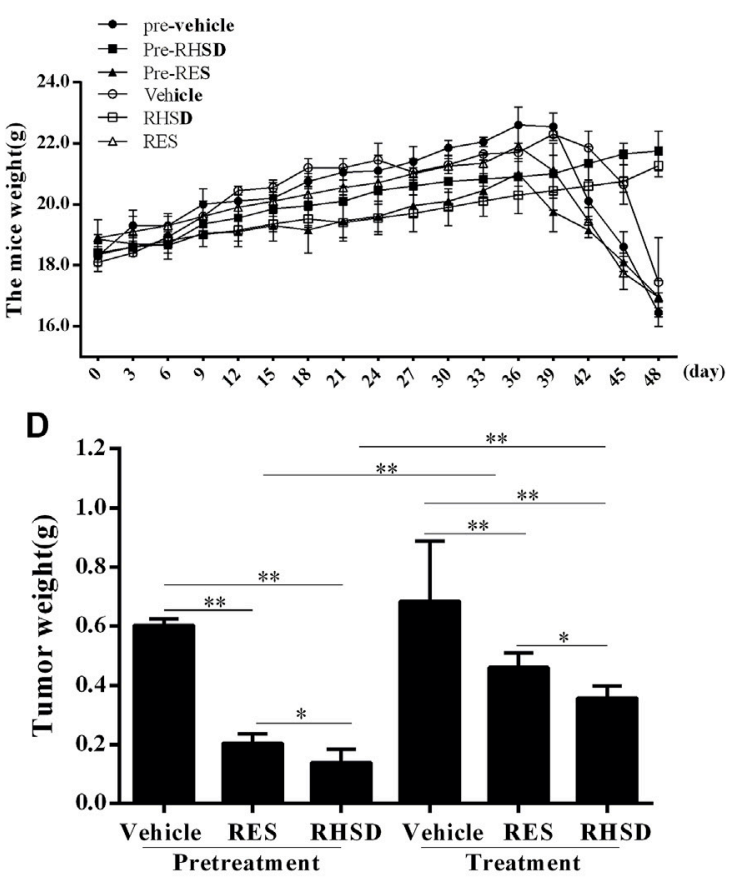

FIGURE 5 | Effects of RES and RSHD on cervical cancer tumor growth in vivo (A) Typical image of subcutaneous tumor formation in nude mice (B) Mice weight (C) Tumor volume (D) Tumor weight. The data were presented as the mean \pm S.D. $n=6 /$ group, ${ }^{\star} p<0.05,{ }^{* \star} p<0.01$. 

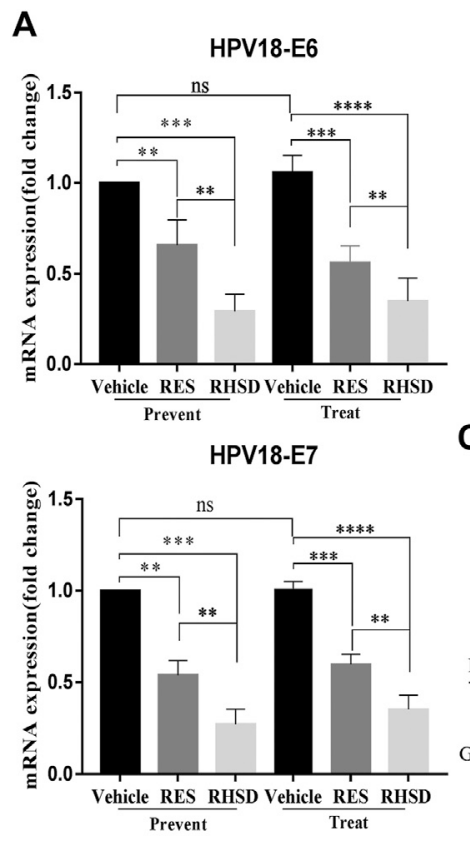

B

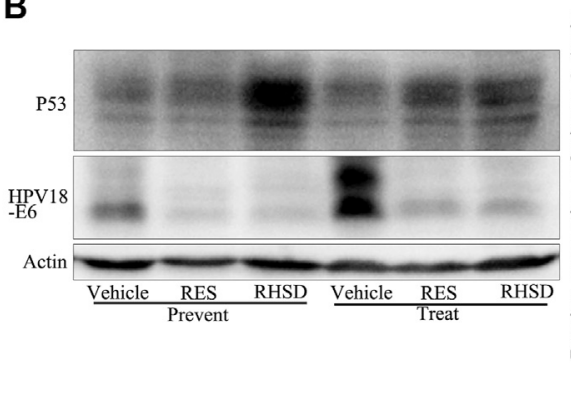

C

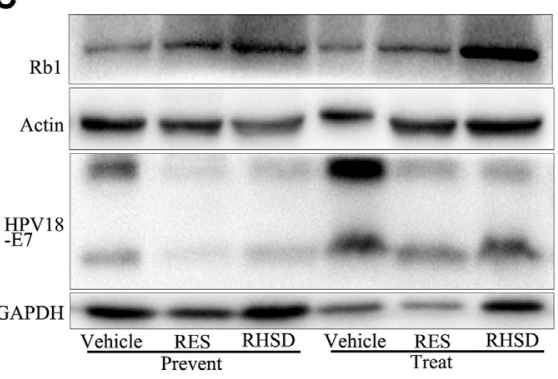

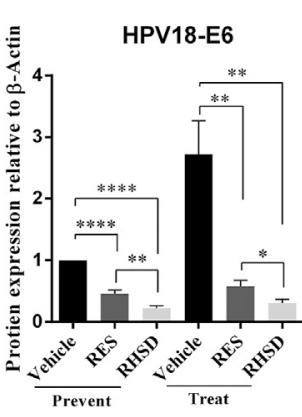
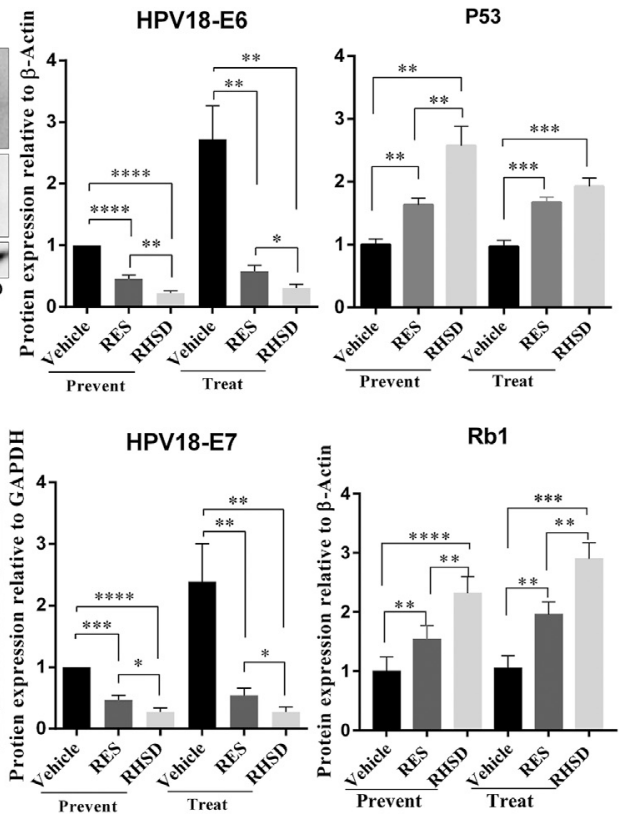

FIGURE 6|Expression of HPV18 E6, E7, P53, and Rb1 in cervical cancer tissues of mice model after RES or RHSD treatment (A) HPV18 E6 and E7 mRNA levels in cancer tissues were determined using real-time RT-PCR (B) HPV18 E6 and P53 protein levels in cancer tissues were determined by Western blot. The histogram on the right is the quantitative analysis of the results (C) HPV18 E7 and Rb1 protein levels in cancer tissues were determined by Western blot. The histogram on the right is the quantitative analysis of the results. The data were presented as the mean \pm S.D. for three different experiments performed in triplicate. ${ }^{\star \star} p<0.01,{ }^{\star \star \star} p<0.001$, and ${ }^{\star \star \star \star} p<0.0001$

shown in Figure 6, the mRNA levels of E6 and E7 treated with RHSD were lower than those treated with RES $(p<0.01)$ compared with the vehicle $(p<0.001$ and $p<0.01$, respectively) in the prevention group (Figure 6A). These findings were similar to the mRNA levels of E6 and E7 in the treatment group (Figure 6A). Consistently, the Western blot results indicated that the protein levels of E6 were significantly decreased by RHSD compared with the vehicle in the prevention and treatment groups $(p<0.01$ and $p<$ 0.0001, respectively; Figure 6B). The levels of protein E7 were also significantly inhibited by RHSD compared with the vehicle group in the prevention and treatment groups $(p<$ 0.01 and $p<0.0001$, respectively). The levels of protein E7 were highly attenuated by RES compared with the vehicle group $(p<$ 0.001 and $p<0.001$, respectively; Figure 6C). Therefore, RHSD was more potent in downregulating E6 and E7 mRNA transcription and protein expression than RES. Tissue immunohistochemical tests showed consistent results (Figure 7). The E6 and E7 protein levels were very high in control tumor sections (Figures 7A,B), but the prevention and treatment groups showed much lower expression of E6 and E7. This result suggested that RHSD and RES could downregulate E6 and E7. The inhibition efficiency of RHSD on E6 and E7 was higher than that of RES ( $p<0.01$ and $p<0.01$, respectively).

P53 and Rb1 have been shown to trigger apoptosis in E6-and E7-harboring cervical cancer cells, respectively (Huh et al., 2007). The expression levels of P53 were improved by RHSD as compared with the vehicle in the prevention and treatment groups $(p<0.0001$ and $p<0.01$, respectively). P53 expression was also upregulated by RES compared with the vehicle $(p<0.01$ and $p<0.001$, respectively). The expression of P53 by RHSD was significantly higher than that by RES in the prevention group $(p<$ 0.01 ; Figure 6B). The levels of Rb1 were strongly upregulated by RHSD than by RES $(p<0.01)$ in the prevention group compared with the vehicle ( $p<0.0001$ and $p<0.01$, respectively). In the treatment group, the levels of $\mathrm{Rb} 1$ were also highly upregulated by RHSD than by RES $(p<0.01)$. In the treatment group, the expression of Rb1 was higher compared with the vehicle ( $p<$ 0.0001 and $p<0.001$, respectively) by RHSD and RES, and Rb1 expression was upregulated by RHSD than by RES $(p<0.001$; Figure 6C). The immunostaining results showed that tumors treated with RHSD had a significantly higher amount of activated P53 and Rb1 than tumors treated with RES and vehicle (Figures 7C,D). The amount of immunostaining cells indicated that in vivo RHSD and RES treatment appeared to activate the process of P53- and Rb1-mediated apoptosis, and the efficiency of RHSD to $\mathrm{P} 53$ and Rb1 was higher than that of RES $(\mathrm{P}<0.01$ and $\mathrm{P}<0.05$, respectively). These results demonstrated that treatment with RHSD possessed a more powerful ability on P53 and Rb1 than treatment with RES. Notably, the transcriptional inhibition of E6 and E7 by RES and RHSD promoted the recovery of P53 and Rb1 expression, respectively. In addition, $\mathrm{H} \& \mathrm{E}$ staining of live and kidney organs showed a normal appearance in treatment and control groups, without any significant signs of toxicity or inflammatory lesions, suggesting RHSD is as nontoxic as RES. (Figure 8). 


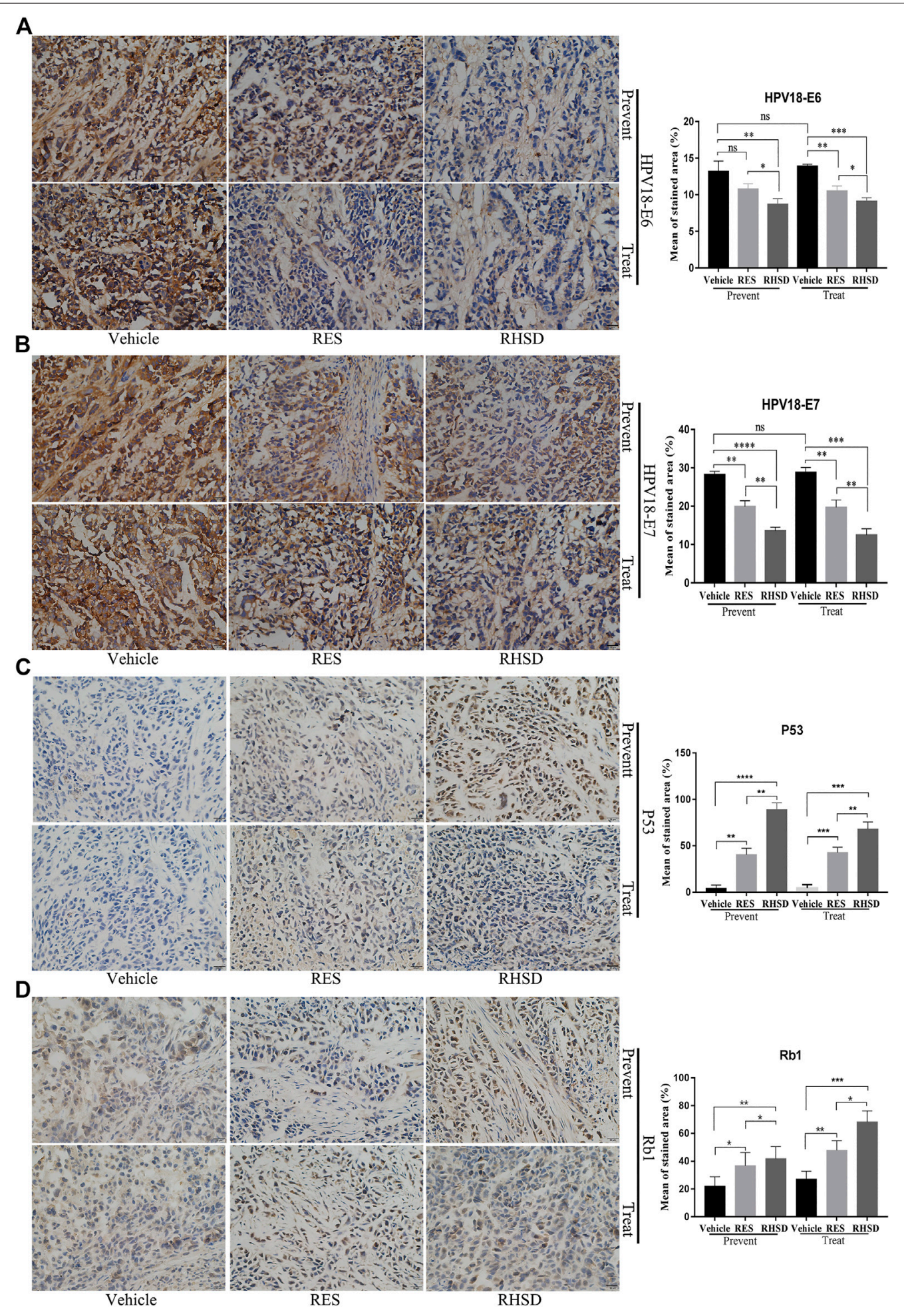

FIGURE 7 | Distribution and expression of HPV18 E6, E7, P53, and Rb1 in cancer tissues. IHC staining of HPV18 E6, E7, P53, and Rb1 protein in tumor samples monoclonal antibody. Tumor sections immunostained with E6 (A), E7 (B), P53 (C), and Rb1 (D) antibodies in mice treated with RES or RHSD (scale bar $=20 \mu \mathrm{m})$. The histogram on the right is the quantitative analysis of the results. The data were presented as the mean \pm S.D. for three different experiments performed in triplicate. ${ }^{\star} p<0.05,{ }^{\star \star} p<0.01,{ }^{\star \star \star} p<0.001,{ }^{* \star \star \star} p<0.0001$. 

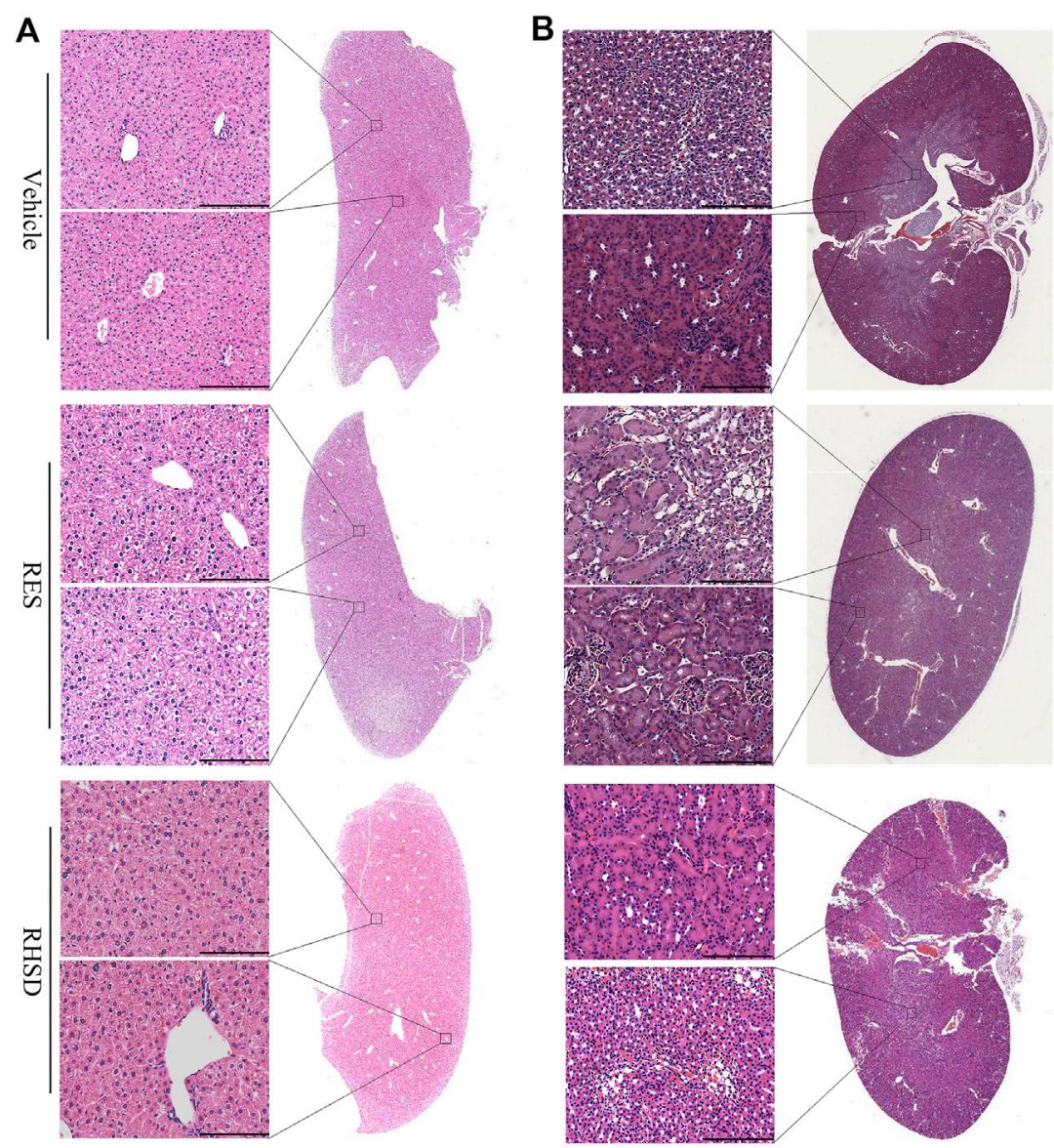

FIGURE 8|RES and RHSD are effective cervical cancer inhibitors with low toxicity. H\&E staining of main organs of tumor-bearing nude mice after treatment. Full section scan and local magnification of Live (A) and kidney (B), Scale bar: $75 \mu \mathrm{m}$.

\section{DISCUSSION}

In this study, we have elucidated for the first time the prevention and treatment of cervical cancer with the RHSD complex using the $\mathrm{BALB} / \mathrm{C}$ female nude mice model of cervical cancer derived from HeLa cells. We demonstrated that the RHSD complex showed a higher efficacy in affecting tumor growth than RES alone. Notably, RHSD showed significant prevention effects compared with RES. Further analysis suggested that the RHSD complex significantly downregulated the HPV oncogenes E6 and E7 in vivo and upregulated the P53 and Rb1 levels. By comparison, RES showed less efficacy on these proteins than the RHSD complex.

RES, well-tolerated polyphenol with low toxicity to humans, is known to have proapoptotic, chemopreventive, and anticancer properties (Fulda, 2010). However, the low bioavailability of RES resulting from its poor water solubility limits its application. Our results showed that the solubility of RES increased (by more than 438.6-fold) significantly after the inclusion complex formed in a ratio of 1:1 with HP- $\beta-C D$, and the dissolution date of complex was also improved than free RES. The crystalline structure of RES was transformed into an amorphous form (proven by UV, IR, PXRD, DSC and ${ }^{1} \mathrm{H}$ NMR).
Previous research demonstrated that RES was able to specifically target the essential oncoprotein E6 and induce cervical cancer cell death in vitro, and decreased the tumor size $(83.5 \%$ compared to control) on TC1 murine model (Chatterjee et al., 2018; Chatterjee et al., 2019). But the efficacy of RHSD on cervical cancer has not been explored. To evaluate the treatment and prevention efficacy of the RHSD complex in an in vivo model of anti-cervical cancer, we established cervical tumors in nude mice and subjected them to RHSD inclusion complexes to evaluate the antitumor effects and mechanism of action compared with RES. At the end of the treatment cycle, RHSD decreased the tumor volume by $86.88 \%$ in the prevention group; this result was higher than that achieved by RES (64.39\%) compared with the control. In the treatment group, the tumor volume was reduced by $40.38 \%$ by RHSD, and this percentage was higher than that by RES (27.4\%). Thus, RHSD complexes demonstrated high efficacy in inhibiting the growth of HeLa cells in vivo compared with RES, and the effect of preventing tumor growth by RHSD was more prominent than that by RES. Our results implied that RES was effective in drastically shrinking a cervical cancer tumor model, which was in accordance with previous report 
(Chatterjee et al., 2019). In addition, the HP- $\beta$-CD enormously improved the pharmacological activity of RES in vivo, indicating the strong potential of RHSD to inhibit tumor growth in a mouse cervical cancer model. Therefore, complexes with HP$\beta-C D$ are a promising strategy for RES delivery systems.

The growth of HPV-positive cancer cells depends on the expression of oncoproteins. The E6/E7 oncoproteins are attractive therapeutic targets because of their rapid inhibitory effect on human papillomavirus-positive cancer cells. This cellular response is related to the regeneration of $\mathrm{P} 53$, which is an Rb1 anti-proliferative protein (Taghizadeh et al., 2019). The binding of E6 and P53 leads to the activation of P53, and the reactivation of P53 can inhibit cell proliferation and induce apoptosis in cervical cancer cells (Xiong et al., 2015). E7 is connected with the retinoblastoma (Rb1) protein; its inhibition leads to the upregulation of Rbl and inhibition of tumorigenicity in CaSki cells (Choo et al., 2000). In the current study, the expression levels of the E6 and E7 oncogenes were analyzed by real-time PCR and Western blot in tissues. We found that RES and RHSD downregulated the mRNA of E6 and E7. The levels of E6 and E7 by RHSD were lower than those by RES, and this trend was also confirmed by Western blot. The difference between RHSD and RES in activating E6 and E7 inhibition was statistically signiffcant. Therefore, this study showed that E6 and E7 might play a crucial role in RHSD's effects on the proliferation of cervical cancer cells. Interestingly, the expression of tumor suppressor proteins P53 and Rb1 were simultaneously increased by RHSD compared with the control group. These findings suggested that RHSD reduced tumor size by inhibiting the E6/P53 and E7/Rb1 pathways.

Given that paraffin blocks are valuable for future studies and review, immunohistochemistry for E6, E7, P53, and Rb1 protein expression was analyzed in this study. Our research revealed that E6 and E7 immunostaining were low in intensity by RHSD and RED compared with the vehicle group. The intensity of E6 and E7 staining was lower in the RHSD group than in the RES group. High intensity of P53 and Rb1 immunostaining was also found in the RHSD group than in the RES group. These results were consistent with the findings of qPCR and Western blot. These results further suggested that the restoration of $\mathrm{P} 53$ and $\mathrm{Rb} 1$ proteins induced by RHSD was dependent on E6 and E7. Moreover, HP- $\beta$-CD could improve the bioavailability of RES, and RHSD could effectively induce apoptosis mediated by the inhibition of E6/E7 expression.

\section{CONCLUSION}

RES has a wide range of biological activity. Phase solubility studies demonstrated that $\mathrm{HP}-\beta-\mathrm{CD}$ is an effective cyclodextrin for the development of an inclusion complex with RES. In in vivo study, we provide strong evidence that RHSD was effective in drastically shrinking a cervical cancer tumor model than free RES, which functioned through inhibition of the E6/P53 and E7/Rb pathways. Therefore, the RHSD inclusion complex has potential for development of a new oral administration drug for the treatment of cervical cancer.

\section{DATA AVAILABILITY STATEMENT}

The datasets supporting the conclusions of this article are included within the article and its additional files.

\section{ETHICS STATEMENT}

Mouse xenograft experiments in this study were complied with the ARRIVE guidelines and were conducted in accordance with the U.K. Animals (Scientific Procedures) Act, 1986 and associated guidelines. This study was approved by the Ethical Committee for Animal Experimentation of Xiangyang No. 1 People's Hospital (NO. 2017DW008).

\section{AUTHOR CONTRIBUTIONS}

$\mathrm{XH}, \mathrm{XS}, \mathrm{PF}$ and MS was responsible for designing the study, data collection and analysis, and preparing the graphs, and was a major contributor to writing the manuscript; $\mathrm{XH}$ and XS were responsible for performing the experiments; LX and NJ was responsible for the statistical analysis; LX and XW rocessed the charts and tables in the revision process of the later articles; $\mathrm{HZ}$ and MS contributed to the critical review of the manuscript; MS and PF supervised and contributed to the critical review of the manuscript. All authors have read and approved the manuscript.

\section{FUNDING}

This investigation was supported by the grants from the National Natural Science Foundation (81903005), the Natural Science Foundation of Hubei Province of China (2019AHB068, 2018CFB701), this investigation was also supported by the Open Project of Hubei Key Laboratory of Wudang Local Chinese Medicine Research (WDCM2018009 and WDCM201918), the Innovative Team Project (2017YHKT02) from the Institute of Medicine and Nursing at Hubei University of Medicine, the Scientific Research Project of Hubei Province Health Committee (ZY2019F028 and ZY2021010), the Science and Technology Development Project of Xiangyang (Project Leader Sang Ming), Hubei Provincial Outstanding Young and Middle-Aged Science and Technology Innovation Team Project (T201813) and the Key R\&D Program of Hubei Provincial Department of Science and technology (2020BCB040).

\section{ACKNOWLEDGMENTS}

The authors thank HZ for his careful modification of the manuscript. We also thank the Director of the Key Laboratory of Wudang Local Chinese Medicine Research (Hubei University of Medicine) XW for providing the facilities to carry out the experiments. I would like to express my gratitude to all those who have helped me during the writing of this thesis. 


\section{REFERENCES}

Adrian, M., Jeandet, P., Breuil, A. C., Levite, D., Debord, S., and Bessis, R. (2000). Assay of resveratrol and derivative stilbenes in wines by direct injection high performance liquid chromatography. Amer J. Enology Viticulture 51, 37-41. doi:10.1016/S0065-2164(00)47008-5

Ao, W., Lin, Z., Wang, G., Li, S., Chen, B., Sui, Y., et al. (2019). Delicaflavone induces apoptosis via mitochondrial pathway accompanying G2/M cycle arrest and inhibition of MAPK signaling cascades in cervical cancer HeLa cells. Phytomedicine 62, p152973. doi:10.1016/j.phymed.2019.152973

Au Yeung, C. L., Tsang, T. Y., Yau, P. L., Kwok, T. T., and Au Yeung, C. L. (2011). Human papillomavirus type 16 E6 induces cervical cancer cell migration through the p53/microRNA-23b/urokinase-type plasminogen activator pathway. Oncogene 30, 2401-2410. doi:10.1038/onc.2010.613

Chatterjee, K., AlSharif, D., Mazza, C., Syar, P., Al Sharif, M., Fata, J., et al. (2018). Resveratrol and pterostilbene exhibit anticancer properties involving the downregulation of HPV oncoprotein E6 in cervical cancer cells. Nutrients 10, 243. doi:10.3390/nu10020243

Chatterjee, K., Mukherjee, S., Vanmanen, J., Banerjee, P., and Fata, J. E. (2019). Dietary polyphenols, resveratrol and pterostilbene exhibit antitumor activity on an HPV E6-positive cervical cancer model: an in vitro and in vivo analysis. Front. Oncol. 9, 352. doi:10.3389/fonc.2019.00352

Choo, C. K., Ling, M. T., Suen, C. K. M., Chan, K. W., and Kwong, Y. L. (2000). Retrovirus-mediated delivery of HPV16 E7 antisense RNA inhibited tumorigenicity of CaSki cells. Gynecol. Oncol. 78 (3), 293-301. doi:10.1006/ gyno.2000.5916

De Sanjose, S., Quint, W. G., Alemany, L., Geraets, D. T., Klaustermeier, J. E., Lloveras, B., et al. (2010). Human papillomavirus genotype attribution in invasive cervical cancer: a retrospective cross-sectional worldwide study. Lancet Oncol. 11, 1048-1056. doi:10.1016/s1470-2045(10)70230-8

Dyson, N., Guida, P., Münger, K., and Harlow, E. (1992). Homologous sequences in adenovirus E1A and human papillomavirus E7 proteins mediate interaction with the same set of cellular proteins. J. Virol. 66, 6893-6902.

Ferlay, J., Soerjomataram, I., Dikshit, R., Eser, S., Mathers, C., Rebelo, M., et al. (2015). Cancer incidence and mortality worldwide: sources, methods and major patterns in GLOBOCAN 2012. Int. J. Cancer 136, E359-E386. doi:10.1002/ijc. 29210

Fulda, S. (2010). Resveratrol and derivatives for the prevention and treatment of cancer. Drug Discov. Today 15, 757-765. doi:10.1016/j.drudis.2010.07.005

Gambuti, A., Strollo, D., Ugliano, M., Lecce, L., and Moio, L. (2004). trans-Resveratrol, quercetin, (+)-Catechin, and (-)-Epicatechin content in south Italian monovarietal wines: relationship with maceration time and marc pressing during winemaking. J. Agric. Food Chem. 52, 5747-5751. doi:10.1021/jf0354895

Ghittoni, R., Accardi, R., Hasan, U., Gheit, T., Sylla, B., and Tommasino, M. (2010). The biological properties of E6 and E7 oncoproteins from human papillomaviruses. Virus Genes 40, 1-13. doi:10.1007/s11262-009-0412-8

He, H., Liu, X., Wang, D., Wang, Y., Liu, L., Zhou, H., et al. (2014). SAHA inhibits the transcription initiation of HPV18 E6/E7 genes in HeLa cervical cancer cells. Gene 553, 98-104. doi:10.1016/j.gene.2014.10.007

Heck, D. V., Yee, C. L., Howley, P. M., and Munger, K. (1992). Efficiency of binding the retinoblastoma protein correlates with the transforming capacity of the E7 oncoproteins of the human papillomaviruses. Proc. Natl. Acad. Sci. 89, 4442-4446. doi:10.1073/pnas.89.10.4442

Hsu, C.-M., Yu, S.-C., Tsai, F.-J., and Tsai, Y. (2019). Characterization of in vitro and in vivo bioactivity of a ferulic acid-2-Hydroxypropyl- $\beta$-cyclodextrin inclusion complex. Colloids Surf. B: Biointerfaces 180, 68-74. doi:10.1016/j. colsurfb.2019.04.020

Hsu, S. C., Huang, S. M., Chen, A., Sun, C. Y., Lin, S. H., Chen, J. S., et al. (2014). Resveratrol increases anti-aging Klotho gene expression via the activating transcription factor $3 / \mathrm{c}$-Jun complex-mediated signaling pathway. Int. J. Biochem. Cel Biol. 53, 361-371. doi:10.1016/j.biocel.2014.06.002

Huh, K., Zhou, X., Hayakawa, H., Cho, J. Y., Libermann, T. A., Jin, J., et al. (2007). Human papillomavirus type 16 E7 oncoprotein associates with the cullin 2 ubiquitin ligase complex, which contributes to degradation of the retinoblastoma tumor suppressor. Jvi 81, 9737-9747. doi:10.1128/jvi. 00881-07
Huibregtse, J. M., Scheffner, M., and Howley, P. M. (1993). Localization of the E6$\mathrm{AP}$ regions that direct human papillomavirus E6 binding, association with $\mathrm{p} 53$, and ubiquitination of associated proteins. Mol. Cel. Biol. 13, 4918-4927. doi:10. $1128 / \mathrm{mcb} \cdot 13.8 .4918$

Kim, Y. S., Sull, J. W., and Sung, H. J. (2012). Suppressing effect of resveratrol on the migration and invasion of human metastatic lung and cervical cancer cells. Mol. Biol. Rep. 39, 8709-8716. doi:10.1007/s11033-012-1728-3

Kulacki, K. J., and Lamberti, G. A. (2008). Toxicity of imidazolium ionic liquids to freshwater algae. Green. Chem. 10, 104-110. doi:10.1039/b709289j

Li, L., Qiu, R. L., Lin, Y., Cai, Y., Bian, Y., Fan, Y., et al. (2018). Resveratrol suppresses human cervical carcinoma cell proliferation and elevates apoptosis via the mitochondrial and p53 signaling pathways. Oncol. Lett. 15, 9845-9851. doi:10.3892/ol.2018.8571

Li, W., Liu, X., Yang, Q., Zhang, N., Du, Y., and Zhu, H. (2015). Preparation and characterization of inclusion complex of benzyl isothiocyanate extracted from papaya seed with $\beta$-cyclodextrin. Food Chem. 184, 99-104. doi:10.1016/j. foodchem.2015.03.091

Liu, J., Qiu, L., Gao, J., and Jin, Y. (2006). Preparation, characterization and in vivo evaluation of formulation of baicalein with hydroxypropyl$\beta$-cyclodextrin. Int. J. Pharmaceutics 312, 137-143. doi:10.1016/j. ijpharm.2006.01.011

Liu, X., Dakic, A., Zhang, Y., Dai, Y., Chen, R., and Schlegel, R. (2009). HPV E6 protein interacts physically and functionally with the cellular telomerase complex. Proc. Natl. Acad. Sci. 106 (1-3), 18780. doi:10. 1073/pnas.0906357106

Liu, Z. X., Li, Y. J., She, G. H., Zheng, X. F., Shao, L. Y., Wang, P. Y., et al. (2020). Resveratrol induces cervical cancer HeLa cell apoptosis through the activation and nuclear translocation promotion of FOXO3a. Pharmazie 75, 250-254. doi:10.1691/ph.2020.0386

Loftsson, T., and Brewster, M. E. (1996). Pharmaceutical applications of cyclodextrins. 1. Drug solubilization and stabilization. J. Pharm. Sci. 85, 1017-1025. doi:10.1021/js950534b

Lucas-Abellán, C., Fortea, M. I., Gabaldón, J. A., and Núñez-Delicado, E. (2008). Complexation of resveratrol by native and modified cyclodextrins: determination of complexation constant by enzymatic, solubility and fluorimetric assays. Food Chem. 111, 262-267. doi:10.1016/j.foodchem.2008. 03.073

Münger, K., and Howley, P. M. (2002). Human papillomavirus immortalization and transformation functions. Virus. Res. 89, 213-228. doi:10.1016/S01681702(02)00190-9

Nubia, M., Fabián, M., Héctor, P., Mónica, M., Adrian, J. C., and Vanden, B. (2004). Incidence, duration, and determinants of cervical human papillomavirus infection in a cohort of Colombian women with normal cytological results. J. Infect. Dis. 190, 2077-2087. doi:10.1086/425907

Riche, D. M., McEwen, C. L., Riche, K. D., Sherman, J. J., Wofford, M. R., Deschamp, D., et al. (2013). Analysis of safety from a human clinical trial with pterostilbene. J. Toxicol. 2013, 1. doi:10.1155/2013/463595

Scavone, C., Bonagura, A. C., Fiorentino, S., Cimmaruta, D., Cenami, R., Torella, M., et al. (2016). Efficacy and safety profile of diclofenac/cyclodextrin and progesterone/cyclodextrin formulations: a review of the literature data. Drugs $R$. D 16, 129-140. doi:10.1007/s40268-016-0123-2

Scheffner, M., Werness, B. A., Huibregtse, J. M., Levine, A. J., and Howley, P. M. (1990). The E6 oncoprotein encoded by human papillomavirus types 16 and 18 promotes the degradation of p53. Cell 63, 1129-1136. doi:10.1016/00928674(90)90409-8

Sun, X., Fu, P., Xie, L., Chai, S., Xu, Q., Zeng, L., et al. (2021). Resveratrol inhibits the progression of cervical cancer by suppressing the transcription and expression of HPV E6 and E7 genes. Int. J. Mol. Med. 47, 335-345. doi:10. 3892/ijmm.2020.4789

Taghizadeh, E., Jahangiri, S., Rostami, D., Taheri, F., Renani, P. G., Taghizadeh, H., et al. (2019). Roles of E6 and E7 human papillomavirus proteins in molecular pathogenesis of cervical cancer. Cpps 20, 926-934. doi:10.2174/ 1389203720666190618101441

Tan, S., de Vries, E. G. E., van der Zee, A. G. J., and de Jong, S. (2012). Anticancer drugs aimed at E6 and E7 activity in HPV-positive cervical cancer. Ccdt 12, 170-184. doi:10.2174/156800912799095135

Tang, P., Ma, X., Wu, D., Li, S., Xu, K., Tang, B., et al. (2016). Posaconazole/ hydroxypropyl- $\beta$-cyclodextrin host-guest system: improving dissolution while 
maintaining antifungal activity. Carbohydr. Polym. 142, 16-23. doi:10.1016/j. carbpol.2016.01.042

Thomas, M. C., and Chiang, C.-M. (2005). E6 oncoprotein represses p53dependent gene activation via inhibition of protein acetylation independently of inducing p53 degradation. Mol. Cel 17, 251-264. doi:10. 1016/j.molcel.2004.12.016

Wei, Y., Zhang, J., Zhou, Y., Bei, W., Li, Y., Yuan, Q., et al. (2017). Characterization of glabridin/hydroxypropyl- $\beta$-cyclodextrin inclusion complex with robust solubility and enhanced bioactivity. Carbohydr. Polym. 159, 152-160. doi:10. 1016/j.carbpol.2016.11.093

Xiong, Y., Chen, L., and Luo, P. (2015). N-benzylcinnamide induces apoptosis in HPV16 and HPV18 cervical cancer cells via suppression of E6 and E7 protein expression. IUBMB life 67 (5), 374-379. doi:10. 1002 /iub. 1380
Zhang, X.-P., Le, Y., Wang, J.-X., Zhao, H., and Chen, J.-F. (2013). Resveratrol nanodispersion with high stability and dissolution rate. LWT - Food Sci. Technol. 50, 622-628. doi:10.1016/j.lwt.2012.07.041

Conflict of Interest: The authors declare that the research was conducted in the absence of any commercial or financial relationships that could be construed as a potential conflict of interest.

Copyright (c) 2021 Hao, Sun, Zhu, Xie, Wang, Jiang, Fu and Sang. This is an openaccess article distributed under the terms of the Creative Commons Attribution License (CC BY). The use, distribution or reproduction in other forums is permitted, provided the original author(s) and the copyright owner(s) are credited and that the original publication in this journal is cited, in accordance with accepted academic practice. No use, distribution or reproduction is permitted which does not comply with these terms. 